\title{
Colonialidade e a branquitude: apontamentos para quebra dos pactos de silêncio na saúde
}

\author{
Coloniality and whiteness: notes for breaking the silent \\ pacts in health
}

Thamires Monteiro

de Medeiros

Instituto de Medicina Social

Hésio Cordeiro - UERJ

thamires.unirio@gmail.com

ORCID: 0000-0002-7679-0390

Mariana Xavier da Silva

Instituto de Medicina Social

Hésio Cordeiro - UERJ

ORCID: 0000-0002-3929-4283

Roberta Dorneles Ferreira

da Costa Silva

Departamento de Saúde Coletiva

- UFRGS

robertadfcosta@gmail.com

ORCID: 0000-0003-2416-0810

Recebido em:10/10/2020

Aceito em:25/06/2021

\section{Resumo}

Este ensaio parte dos mitos fundantes da colonialidade para aprofundar o entendimento a respeito de um deles: a produção do "outro" racializado, pelo branco-europeu na modernidade, e sua autodeclaração como referência (fictícia) de humanidade. A partir desta constatação destacamos como tal invenção se sustenta por meio de processos de naturalização de sí, e para isso evocamos o conceito e práticas da branquitude, como ferramenta que se reatualiza para a manutenção das estruturas de poder (materiais e subjetivas) do racismo. Apontamos, por fim, a necessidade de estratégias de quebra dos pactos de silêncio da branquitude, e como essa estrutura projeta desigualdades nos campos da formação de profissionais de saúde, na construção de políticas de saúde e nas práticas de saúde.

Palavras-chave: Colonialidade, Branquitude, Racismo, Saúde.

\section{Abstract}

This essay starts from the founding myths of coloniality to deepen the understanding regarding one of them: the production of the racialized "other", by the white-European in modernity, and its self-declaration as a (fictitious) reference of humanity. Furthermore, we highlight how such an invention is sustained by means of naturalization processes, and for that we evoke the concept and practices of whiteness identity, as a tool that is updated to maintain the power structures (material and subjective) of racism. Finally, we point out the need for strategies to break the whiteness silence pacts, and how this structure projects inequalities in the fields of the training of health professionals, in the construction of health policies as well as during health practices.

Key words: Coloniality, Whitness Studies, Racism, Health, Whitness. 


\section{De onde viemos e falamos}

A partir dos lugares sociais que ocupam as autoras deste trabalho, qual sejam, (também) a de trabalhadoras e estudiosas da área da Saúde Coletiva, produzimos alguns apontamentos sobre como na nossa área de atuação e estudo alguns pactos de silêncio da branquitude se produzem, reproduzem e se reatualizam. Ressaltamos, no entanto, que o que apontamos é ínfimo frente a amplitude da necessidade da quebra destes silêncios históricos.

As pontuações aqui realizadas se produzem a partir dos corpos de três trabalhadoras da saúde, com marcas sociais e históricas distintas e atravessados de maneira radicalmente diferente pelos privilégios (aos brancos) e violentas e inestimáveis desvantagens (aos negros) produzidos pela branquitude. Nos importa o esforço de compreensão acerca de como nossa escrita se produz situada em nossas marcas sociais e históricas, e por isso nos apresentamos, mesmo que minimamente.

Thamires é mulher branca, cisgênera e suburbana da Penha, Rio de Janeiro. Graduada em Enfermagem, e pós-graduada em Saúde da Família e Saúde Coletiva, contou desde graduação com políticas de permanência e apoio à pesquisa. Mariana é uma mulher preta, jovem, periférica, nascida e criada a $66 \mathrm{~km}$ de distância do centro do Rio de Janeiro, no bairro de Santa Cruz. Se forma Assistente Social após contar com o apoio de um pré-vestibular social para o ingresso na universidade e com as políticas de permanência para sua conclusão. Roberta é mulher branca, cisgênera, do Alegrete: fronteira oeste do Rio Grande do Sul. Graduada em Farmácia, por uma instituição pública, teve a oportunidade de viver a ampliação do acesso ao ensino público no Brasil e o incentivo a carreira acadêmica.

Nos encontramos no programa de pós-graduação em Saúde Coletiva do Instituto de Medicina Social Hésio Cordeiro, da Universidade do Estado do Rio de Janeiro, compromissadas desde graduação com a pauta ética e política da saúde como um direito humano e no ensejo de construir esta pauta no Brasil, por meio do Sistema Único de Saúde.

Devido nossa insersão na saúde, nos é cara a compreensão sobre como neste campo, produzimos e reproduzimos os sentidos da colonialidade, seja no âmbito do serviço de saúde, da gestão, da formulação de políticas ou da formação. Nosso interesse sobre branquitude, especificamente, se dá, dentre outros motivos, a partir da observação de como, em nossas instituições, corpos brancos têm produzido reatividade ao serem contestados, seja no âmbito institucional, coletivo ou individual sobre práticas e discursos racistas.

\section{Os mitos fundantes da colonialidade e necessidade de sua compreensão}

Consideramos fundamental a compreensão acerca dos processos de naturalização dos sentidos, estruturas e institucionalidades da colonialidade, pois compreendemos que uma matriz produtora de tamanhas violências, genocídios e devastações, teve e tem de contar com um arcabouço sofisticado de processos de naturalização de si e com diversidade de tecnologias de dominação. Ou seja, para a colonialidade se efetivar, processos de construção de mitos se construíram e se sustentam secularmente.

Aqui entendemos mito como a construção de sentido provocada por meio da distorção ou apagamento da historicidade das coisas, tornado-as naturais (BARTHES, 2001). Os mitos fundantes da colonialidade são muitos. O homem-branco-cristão-europeu-moderno constrói a si como (suposta) referência espistêmica-ética-estética-política de humanidade e utiliza de arcabouço bélico e ideológico para legitimar a imposição de si e a subjugação do "outro" racializado, tanto no nível material quanto subjetivo. E constrói variados argumentos estapafúrdios para subsidiar sua dominação, a partir da invisibilização dos seus marcadores sociais, ao mesmo tempo que supervaloriza esses marcadores no que ele constrói como o "outro".

A bula papal de 1455 é exemplar na afirmação do mito de construção do homem-branco-europeu-cristão como referência de humanidade, que pode então a partir de seu lugar de poder-referência, subjugar todas e todos de outras terras a seu mando e escravização para imposição da sua fé e de si mesmo. O papel da igreja 
católica foi fundamental, para construir bases para justificar a escravização dos povos africanos, quando a igreja enuncia os povos deste continente como "amaldiçoados" por serem "descendentes de Caim" que matou seu irmão Abel, tendo o sofrimento legitimado e apontado até mesmo como uma possível "redenção cristã". Assim, a agenda imperialista se efetiva no subsídio desta construção ideológica que resulta em quase 4 séculos de sequestro e escravização de povos de África no Brasil, para além dos genocídios e escravizações nos interiores do país, direcionadas aos povos originários. Processo que gerou violências, genocídios, epistemicídios e desvantagens históricas incalculáveis e até hoje nem mesmo minimamente reparadas.

Mais pra frente na história, no século XIX, surge o racismo científico (MATOS, 2010), uma "nova narrativa" para constituir e reafirmar o mito do homem-branco-europeu-cristão como referência de humanidade. Mentiras se produzem a respeito de diversas características do corpo do "outro" racializado. Busca-se por marcas biológicas que justifiquem a suposta inferiodade, como a partir de medidas de partes do corpo. Toda sorte de absurdos são produzidos na construção da narrativa que se pretendia científica para subsidiar o racismo.

A partir do século XX, pesquisas no campo da genética, biologia e bioquímica concluíram que o conceito biológico de raça se revela inadequado à Ciência. Por outro lado, mesmo que o conceito de raça seja insustentável do ponto de vista bilógico-científico, o seu uso nos séculos XVIII-XIX pelos naturalistas não se restringiu a critérios físicos mas também incluiu atributos valorativos absurdos como "menos honesta e inteligente", "mais sujeita a escravidão" (MUNANGA, 2000). A falência da produção de diferença racial no nível biológico dá abertura a outras estratégias discursivas de manutenção do mito da superioridade branca e assim esta farsa tem se reatualizado através da história. O mito se refaz sempre enfrentando as fortes resistências seculares dos povos submetidos à noção de racialização, mas também sempre reproduzindo suas ferramentas de violência-atualização.

O capitalismo, projeto político econômico da colonialidade vai se produzir enquanto projeto global intrínseco a construção ideológica do "outro" racializado, e também a partir de outros mitos. Se produz discursivamente como viável mesmo com exploração projetada para ser infinita, de recursos finitos. Traça, no seu arcabouço ideológico, uma falsa historicidade linear, como se todos países do globo tivessem capacidade para "competir" e "se desenvolver", ou "progredir", ignorando não somente a inviabilidade da exploração infinita dos recursos naturais, como as amarras políticas e econômicas de um modelo desenhado para garantir economias dominantes e dependentes, centros e periferias.

Um sofisticado arcabouço ideológico vem sustentando a produção e reprodução destes mitos coloniais, com o uso de ferramentas que buscam tornar naturais e invisibilizadas as violências e extremas desigualdades provocadas por este modelo. Atualmente, a naturalização das hierarquias de poder (materiais e subjetivas) marcadas por raça, classe e gênero, por exemplo, se expressam na resistência de parcela da população e de formuladores de políticas no que tange a produção de medidas de reparação e proteção para os grupos historicamente assolapados pela estrutura da colonialidade. Esta afirmativa se expressa desde a resistência à estipulação de cotas raciais nas universidades a não estruturação de medidas de proteção específicas para COVID-19 (SARS-COV2) que considere as marcas das desigualdades. O que vem resultando em uma conjuntura na qual a pandemia afeta e mata mais as populações e territórios vulnerabilizados escancarando as desigualdades e suas intersecções na sociedade brasileira (MARINO et al., 2021; MARINO et al., 2020; REDE NOSSA SÃO PAULO, 2021; FBSP, 2021). O não manejo de políticas de prevenção, acesso a tratamento e garantia de direitos à populações racializadas e vulnerabilizadas em meio a pandemia revela uma reatualização do projeto de colonialidade de naturalização da morte destes corpos.

Os dados que evidenciam as violências contra as mulheres e população LGBTQIA+ (agudizadas em contexto pandêmico) revelam a capilaridade no tecido social do mito trazido pela colonialidade acerca dos seus binarismos, como aquele acerca do que é "mulher" ou "homem". Outros esquemas também se constroem nessa lógica como "bem x mau"; "deus x diabo", como tem nos apontado continuamente Antônio Bispo 
dos Santos ${ }^{1}$ em suas falas e escritas. E toda leitura cosmológica que escape a estas composições são alvo de tentativas de extermínio para que sejam suprimidas da linguagem.

Sabe-se, no entanto, que apesar da investida colonial em tornar invisíveis seus mitos, aporte crítico, principalmente advindo das lutas sociais seculares, já tem nos apontado evidências suficientes sobre como a estruturação do sistema-mundo colonial-capitalista determina diferentes padrões de nascimento, vida, adoecimento e morte à pessoas e populações, bem como padrões de destruição do meio ambiente. De forma que é possível, por exemplo, não somente prever processos de adoecimento como também compreender suas raízes históricas, e determinações sociais. Tais raízes e determinações tem nos apontado que estes processos se situam histórica e socialmente, e que por isso, podem ser modificados. A colonialidade, apesar de se pretender a-histórica, não o é. Sua história é passível de observação e crítica, pois os capitalistas-racistas-patriarcais-colonizadores não só produziram sua ideologia a luz do dia como a atualizam na atualidade, apesar de o fazerem ao mesmo passo que produzem estratégias de invisibilização e naturalização de sua violência.

Apesar de não exaurir todos os mitos que a colonialidade produz, até aqui, buscamos inicialmente apontar a profundidade de alguns deles e sobre como se fundam, sustentam e reatualizam o projeto colonial. Neste texto queremos dar ênfase a como, em nossa realidade social, seja no âmbito público ou privado, contribuímos, por meio do agir da branquitude, para processos de silenciamento e naturalização de uma das faces da colonialidade: o racismo, o pilar colonial.

\section{A colonialidade, seu Estado-institucionalidade e o "não ser" por ela produzido}

Entendemos a colonialidade na tríade modernidade-colonialidade-capitalismo, por entender que o processo iniciado no emergir moderno desenvolveu-se de maneira a estruturar as formas de funcionar do capitalismo, e que este processo se estende até os dias atuais, dado que as relações de colonialidade nas esferas econômica e política não findaram com o fim do colonialismo (BALLESTRIN, 2013). A estruturação do capitalismo global, seus centros e periferias e as noções de norte e sul do mundo, são construídas na extensão das colonizações até a atualidade.

Sobre modernidade, concordamos com Dussel (1995) ao afirmar que a mesma se origina no início da expansão europeia, especificamente em 1492, originando a noção de Centro-Periferia: no plano nacional (elites-massas, burguesia nacional-classe operária e povo); no plano erótico (homem-mulher); no plano pedagógico (cultura imperial, elitista, versus cultura periférica, popular, etc.) e no plano religioso (o fetichismo em todos os níveis) (DUSSEL, 1995).

A expansão colonial iniciada com as grandes navegações e o "descobrimento" das Américas - posteriormente incrementada com o neocolonialismo do final do século XIX, que propiciou a repartição da África e Ásia -, é entendida como condição sine qua non para o surgimento, existência e manutenção do capitalismo industrial, por exemplo. Ressalta-se ainda que a extinção do colonialismo histórico-político nas Américas com a construção de nações independentes no século XIX, bem como na África e Ásia, por intermédio da descolonização em meados do século XX, não foi suficiente para a emancipação político-econômica e cultural dos países periféricos. Assim, a acumulação primitiva colonial, longe de ser uma pré-condição do desenvolvimento capitalista, foi um elemento indispensável da sua dinâmica interna e posterior continuidade (ASSIS, 2014).

Assis (2014) aponta a continuidade das relações centro-periferia que tem se estruturado por meio de frequentes deslocamentos de capital e do avanço de corporações transnacionais e conglomerados financeiros, que produzem novas formas de exploração do trabalho e de recursos naturais territorializados. O Estado e o mercado representam, neste desenho, dimensões complementares de um processo unitário que impulsiona

1 Antônio Bispo dos Santos é quilombola piauiense, escritor - lavrador de palavras, ativista político e militante quilombola, integrante da rede de mestres e docentes da Universidade de Brasília. Dentre obras e generosas falas e aulas públicas, destacamos o livro "Colonização, quilombos, modos e significações" que se encontra em segunda edição pela editora Ayô, em 2019. 
a expansão do capitalismo por meio da perpetuação das relações centro-periferia (ASSIS, 2014). Assim, as zonas periféricas do capital mantêm-se numa situação colonial, ainda que já não estejam sujeitas a uma administração direta dos antigos colonos (GROSFOGUEL, 2008).

Essa relação apontada por Assis (2014) demonstra que a expansão e a base para a consolidação do capitalismo passa, essencialmente, pela forma de colonização criada e imposta pelos europeus. Não por acaso, que essa forma de operar, não só foi a base, mas também a manutenção do capitalismo. Se analisarmos os vários momentos de crise do capitalismo, veremos que esse colonialismo-extrativista retorna de forma muito expressiva. Ao analisarmos o período de crise do capital, imposto pela Segunda Guerra à Europa, percebemos um retorno à prática colonial extrativista marcada pelo período neocolonial. Para que o Welfare State e a as políticas de social democracia pudessem reerguer a Europa, mais uma vez, sangue negro foi derramado no continente africano.

Assim, a colonialidade opera até os dias atuais dando continuidade ao arcabouço de dominação inaugurado pelo colonialismo.

Definida como ponto de chegada universal, a modernidade foi no passado atrelada ao projeto de colonização, ao passo que hoje, já em outra roupagem, responde ao projeto da colonialidade, porque preserva e carrega os elementos classificatórios do mundo e os atualiza na dinâmica histórica (OLIVEIRA, 2018, p. 42).

Fundamental para este texto é a compreensão de que a efetivação do projeto moderno-colonial-capitalista só foi possível por meio da retirada da condição de humanidade do colonizado e colonizada, ou do "outro" que não o referencial branco-masculino-europeu, com ênfase para a negação da condição humana para as populações negras e indígenas, submetidas a escravização e genocídios seculares. Assim, os âmbitos do poder mundial capitalista foram atravessados pela noção de raça (como instrumento para retirada da humanidade) criada pelo europeu, uma maneira e um resultado da dominação colonial moderna (PETRUCCELLI, 2013).

O arcabouço ideológico que institui os Estados-nação modernos acompanha a história da colonialidade e do capitalismo e tem por base seus valores epistêmicos filosóficos. Tal Estado surge a partir do mito produzido pelo "teatro da razão" (SILVA, 2014) da universalidade científica e jurídica do século XVII, que produziu tal entidade como aquela que é "uma comunidade humana que pretende com êxito, o monopólio do uso legítimo da força física dentro de um determinado território" (WEBER, 2002, p. 56). Compreender o arcabouço estruturante deste Estado dá pistas a compreensão de suas institucionalidades.

Segundo Silva (2014), a razão universal proposta na modernidade governa como necessitas na forma de força e ordem, de forma a restringir, regular ou limitar. A autora cita Hobbes para situar a criação do Estado, apontando que em nome de uma suposta paz e segurança cria-se o Estado: "de acordo com os primeiros pensadores do "contrato social", o racional cria a sociedade política, abandonando assim, a liberdade gozada no "estado de natureza".

Em suma, a autodeterminação e a autopreservação reconfiguram a violência que constitui o núcleo instável do Direito e a armadura rígida do Estado. E ela opera nos usos da ideia de universalidade para fundamentar qualquer determinação (decisão ou julgamento) com relação ao "mundo das coisas" ou às "sociedades dos homens" (SILVA, 2014, p. 76).

A Europa edificou-se à base da subordinação, humilhação e dependência da América Latina e África. Enquanto a modernidade alumiou para os europeus contratos de organização da vida social, aos seres destituídos de estatuto ontológico, o que foi oferecido foi a vigência de contratos de subordinação (RUFINO, 2019, p.29).

A produção intelectual iluminada que teorizava o Estado moderno produzia-se também pautando o conceito de raça, tão caro à modernidade. 
O desenvolvimento da ideia e da ideologia da raça coincidiu com a ascensão da ciência nas culturas americana e europeia no Século XVIII. Grande parte da inspiração para o progresso do conhecimento foi creditada ao período do Iluminismo. Apesar das ideias bastante liberais acerca da potencialidade de todos os povos, mesmo selvagens, do início desse século, também se encontram afirmações sobre a "natural" inferioridade dos africanos por filósofos, como John Locke (1632-1704), Charles de Secondat, barão de Montesquieu (1689-1755), Voltaire (1694-1778), David Hume (1711- 1776) e Immanuel Kant (1724-1804), e pelo político Thomas Jefferson (1743-1826) (PETRUCCELLI. 2013, p. 18).

Durante séculos se lutou para estabelecer uma diferença binária entre dois tipos de pessoas (...) Vejam como Edmund Burke escreveu para o historiador William Robertson em 1777: "Não precisamos mais recorrer à história", afirmou, "para traçar o conhecimento da natureza humana em todas as suas fases e períodos. Por quê? Porque agora o grande mapa da humanidade está todo na estrada e não há estado ou gradação de barbárie ou modo de refinamento que não esteja simultaneamente sob nossa vista." Este é o olhar panóptico do Iluminismo: tudo, toda a criação humana está, por assim dizer, sob o olho da ciência. E, neste âmbito, é possível marcar as diferenças que realmente importam. E quais são? "As civilidades muito diferentes da Europa e da China; a barbárie de Tartary e da Arábia; e o estado selvagem da América do Norte e da Nova Zelândia." Meu argumento não diz respeito à ciência em si, mas ao que estiver no discurso de uma cultura que fundamenta a verdade sobre a diversidade humana, que abre o segredo das relações entre natureza e cultura, que desata o nó enigmático da diferença humana que importa. O que importa não é que contenham a verdade científica sobre a diferença, mas que funcionem como fundamento do discurso sobre a diferença racial. Fixam e estabilizam o que de outra maneira não haveria como ser fixado ou estabilizado. Asseguram e garantem a verdade das diferenças discursivamente construídas" (HALL, 2013, p.1).

Petruccelli (2013) indica que a produção intelectual iluminista incluía opiniões depreciativas a respeito de pessoas advindas da África e também sobre povos originários, com base em impressões subjetivas provindas de fontes secundárias como viajantes, missionários e exploradores. A legitimação intelectual da supremacia branca aparecia como naturalmente justificada pelas ideias hegemônicas para fundamentar a exploração de povos. Destaca-se assim que a produção do Estado soberano que detém a legitimidade da operação da força nasce pari passu à construção da noção de um “outro" inferior, desprovido de humanidade.

Silva (2016) desenha a produção de diferença exacerbada na modernidade a partir de suas referências filosóficas fundantes. A autora traça uma linha história de herança filosófica desde os primórdios da filosofia natural (Galileu e Descartes) e da física clássica (Newton). Segundo a pensadora, “destes filósofos herda-se o entendimento da matéria da Antiguidade com a noção que compreende o corpo a partir de conceitos abstratos que estariam presentes no pensamento, como solidez, extensão, peso, gravidade, e movimento no espaço e no tempo" (p.59). Assim, filósofos como Galileu se apoiaram na necessidade característica da matemática (mais precisamente geometria) como base para a certeza (SILVA, 2016).

Seguindo a linha histórica, a autora (SILVA, 2016) aponta que Descartes introduziu no século XVII uma separação entre a mente e o corpo. Nesta separação, a mente humana, devido à sua natureza formal, "também adquire a capacidade de determinar tanto a verdade sobre o corpo do homem, quanto sobre tudo aquilo que compartilha de seus atributos formais, como solidez, extensão e peso" (SILVA, 2016, p. 60).

Essa separação é justamente o que será consolidado no modelo do sistema filosófico de Kant, feito a partir do programa de Newton, especialmente a ideia de que o conhecimento consiste na identificação das forças limitantes, ou leis que determinam o que ocorre às coisas observadas e aos acontecimentos. 
A realização de Kant, o desenho de um sistema que se baseava fundamentalmente na capacidade determinante da razão e não em um criador divino, perturbou seus contemporâneos, que viram aí a possibilidade de uma determinação formal também se tornar um descritor das condições humanas, constituindo uma ameaça mortal ao ideal da liberdade humana.

No entanto, dois elementos inter-relacionados do programa kantiano continuam a influenciar projetos epistemológicos e éticos contemporâneos:

(a) separabilidade, isto é, a ideia de que tudo o que pode ser conhecido sobre as coisas do mundo está compreendido pelas formas (espaço e tempo) da intuição e as categorias do Entendimento (quantidade, qualidade, relação, modalidade) - tudo o mais a respeito delas permanece inacessível e é irrelevante para o conhecimento; e consequentemente

(b) determinabilidade, a ideia de que o conhecimento resulta da capacidade do Entendimento de produzir constructos formais, que ele pode usar para determinar (isto é, decidir) a verdadeira natureza das impressões sensíveis compreendidas pelas formas da intuição (SILVA, 2016, p. 60).

A autora segue a linha temporal apontando que após a publicação de obras de Kant, Hegel (1777-1831) trabalhou a questão da ameaça à liberdade com a proposta de um sistema filosófico que inverte o programa kantiano com um método dialético.

Esse método empreende dois feitos: (a) a noção de realização, na qual corpo e mente, espaço e tempo, Natureza e Razão, são duas manifestações de uma mesma entidade, o Espírito, ou a Razão como Liberdade e (b) a noção de sequencialidade, que descreve o Espírito como movimento no tempo, um processo de autodesenvolvimento, e a História como a trajetória do Espírito. Com esses passos, ele introduz uma conformação temporal da diferença cultural como realização de momentos distintos do desenvolvimento do Espírito, cujo ápice seria representado pelas configurações sociais europeias pós-iluministas (SILVA, 2016, p. 60).

Segundo a autora, a noção de sequencialidade, introduzida pela trajetória do espírito em Hegel, inaugura um ponto de chegada localizado no homem europeu moderno e sua sociedade, o que possibilita a compreensão de diferença cultural e diferenciação da humanidade em classificações humanas e não humanas. A autora aponta ainda a determinação deste sistema de pensamento às formas pelas quais as instituições modernas são estruturadas, e como tal sistema subsidiou a criação de Estados-nação "civilizadores"/colonizadores, e a própria escravidão secular de povos de África (SILVA, 2016).

Sob a égide da historicidade, o modo de transformação do espírito, a universalidade, como um princípio rege a moralidade objetiva por completo apenas porque descreve a totalidade ético-jurídica, configurada pela nação e pelo Estado - no final do século XIX consolidado na entidade política (ético-jurídica) híbrida, qual seja, o Estado-Nação -, o que marca o fim da trajetória do espírito (SILVA, 2014, p. 90).

Denise (SILVA, 2014) afirma que este constructo forma o arcabouço da racialidade que apreende o corpo e o território - no século XIX como formas ou “tipos raciais” (SILVA, 2016, p. 91), que produz como significantes mentes humanas distintas:

O "eu" transparente, o branco/europeu do pós-Iluminismo, aqueles que efetivam/expressam a realização do Espírito, e o "eu" sujeitado, "os outros em relação à Europa", aqueles 
cujas mentes efetivaram/expressaram os efeitos da razão produtiva conforme compreendida pelas ferramentas de produção ("leis" e "formas") do entendimento (SILVA, 2014, p. 91).

Afirma-se que na ciência que aborda o corpo e o território humano, inscrita nestes arcabouços, a autodeterminação continua sendo atributo da mente racional, "a qual existe no reino da liberdade, onde a transcendentalidade é efetivada, a saber, onde residem as coisas ético-jurídicas da razão, sujeitos modernos cujos pensamentos, ações e territórios reconfiguram a universalidade" (SILVA, 2014, p. 91).

Como esse arcabouço político-simbólico que reconfigura um efeito-poder da necessitas (formalização) produz os "outros em relação à Europa" em situação de afetabilidade, sujeitos que não atuam na moralidade objetiva. Nele, os outros em relação à Europa habitam sozinhos os domínios da necessitas, completamente sujeitados ao poder limitador/regulador que produz e determina as partes e movimentos dos seus corpos, assim respondendo pela qualidade inferior de suas mentes, o que é significado nos modos de existência que se desenvolvem em seus territórios. A racialidade produz tanto o sujeito da moralidade objetiva, que é protegido nos salões da lei e pelas forças do Estado, quanto os sujeitos da necessitas, os sujeitos raciais subalternos cujos corpos e territórios, o presente global, se tornam lugares onde o Estado faz uso da sua força de autopreservação (SILVA, 2014, p. 91).

A contribuição de Denise (SILVA, 2014; SILVA, 2016) para pensar a construção do Estado moderno calcado numa dada noção de racialidade é fundamental para pensar a construção social do Brasil e o operar do Estado brasileiro, principalmente no que se refere o perpetuar do mito da democracia racial no tecido social desta nação e o atuar do Estado para sua autopreservação por meio do controle e extermínio de populações específicas.

O processo de racialização foi fundante nos processos de colonização e ainda é fundante na atuação de Estados nacionais atualmente, para sua autopreservação. Apontamos que a busca pela compreensão sobre a construção social brasileira e sobre o operar do Estado Brasileiro precisa passar pelo entendimento de sua raiz moderna-colonial-capitalista.

Em territórios de existência de sujeitos raciais subalternizados por meio das ferramentas de racialidade (diferença racial e cultura) o Estado vem atuando para sua preservação por meio da execução de violências e morte (SILVA, 2014).

regiões urbanas economicamente desfavorecidas da população negra e parda (i.e., as favelas do Rio) como territórios sujeitados, regiões políticas (ético-jurídicas) com/sem lei. Como elas sempre já são construídas como zonas nativas da violência, é lá onde o Estado deve necessariamente mostrar a sua face de autopreservação.

Como estes existem na (in)diferença moral, a racialidade inscreve nesses territórios qualquer um, todo mundo, qualquer pessoa, a entidade (ético-jurídica) que ali se encontra não configura o sujeito da moralidade objetiva, as pessoas autodeterminadas que a lei e o Estado protegem; ante essas estruturas, esses sujeitos raciais subalternos não são ninguém, são não seres (SILVA, 2014, p. 100).

Mbembe (2018) aponta o padrão de organização estatal moderna que não se dá para garantir bem estar geral mas, pelo contrário, impõe a morte, controle ou condições de morrer a um determinado grupo para garantir a subsistência e proteção de outro, no sentido de garantir uma ordem social que favorece estes últimos.

$\mathrm{Na}$ sociedade brasileira essas práticas se evidenciam a partir das relações que o próprio Estado-burguês-colonial exerce sobre as relações de trabalho e condições de cidadania, ou melhor, da ausência delas evidenciadas a partir da crise do COVID-19 (SARS-COV2) em 2020 e 2021. Saflate (2020) no texto Estado suicidário, discute o papel do Estado e sua relação amistosa com o mercado: 
É claro que tal Estado se funda nessa mistura tão nossa de capitalismo e escravidão, de publicidade de coworking, de rosto jovem de desenvolvimento sustentável e indiferença assassina com a morte reduzida a efeito colateral do bom funcionamento necessário da economia. Alguns acham que estão a ouvir empresários, donos de restaurantes e publicitários quando porcos travestidos de arautos da racionalidade econômica vêm falar que pior que o medo da pandemia deve ser o medo do desemprego.

$\mathrm{Na}$ verdade, eles estão diante de senhores de escravos que aprenderam a falar business english. A lógica é a mesma, só que agora aplicada à toda a população. O engenho não pode parar. Se para tanto alguns escravos morrerem, bem, ninguém vai realmente criar um drama por causa disso, não é mesmo? E o que afinal significa 5.000, 10.000 mortes se estamos falando em "garantir empregos", ou seja, em garantir que todos continuarão sendo massacrados e espoliados em ações sem sentido e sem fim enquanto trabalham nas condições as mais miseráveis e precárias possíveis? (SAFLATE, 2020, p. 4)

Neste contexto, a construção fictícia da noção do "outro" ou "aquele que pode ser executado" como o inimigo, é fundamental para validar socialmente seu controle, vigilância e extermínio e parece ser justamente essa narrativa que vem sendo construída, por exemplo, até hoje, sobre as populações que vivem em favelas do Rio de Janeiro para a validação social da política de segurança pública que vem lhes retirando a vida diariamente na cidade.

O processo de favelização perpassa questões territoriais e abrange as condições socioeconômicas, sociais, raciais e outras questões dentro de um contexto maior do que o aparente. Dados do Instituto Pereira Passos - IPP informam que $20 \%$ da população da cidade reside em favelas, o Estado compreende as favelas como como um espaço não pertencente à cidade sendo necessária sua regularização e sobretudo atuando no viés de regulação. É possível identificar a expressão das desigualdades através do cenário e perceber que as favelas detém a maior concentração de população não branca da cidade.

Neste cenário ético-jurídico, os corpos de jovens negros assassinados não são considerados como em contexto de guerra urbana, ou algo que o valha, pois a existência de sujeitos raciais subalternizados como resultado das ferramentas da racialidade (diferença racial e cultura) se revela em territórios onde o Estado burguês atua apenas para sua própria preservação (SILVA, 2014).

Reforçando a noção acerca do "outro" destituído de humanidade na modernidade, Frantz Fanon desenvolveu a noção de "zona do não ser" na colonialidade como "uma região extraordinariamente estéril e árida", habitada pelo negro, no qual o negro não é considerado humano, tratando-se de um "não ser" (FANON, 2008).

No contexto colonial, Fanon adiciona:

Não basta ao colono limitar fisicamente, com o auxílio de sua polícia e de sua gendarmaria, o espaço do colonizado. Como que para ilustrar o caráter totalitário da exploração colonial, o colono faz do colonizado uma espécie de quintessência do mal. A sociedade colonizada não é apenas descrita como uma sociedade sem valores. Não basta ao colono afirmar que os valores desertaram, ou melhor jamais habitaram, o mundo colonizado. O indígena é declarado impermeável à ética, ausência de valores, como também negação dos valores (FANON, 1979, p. 30, 31).

Quijano (2005) aponta a centralidade da noção de raça, introduzida pelo europeu para a sustentação dos argumentos da distinção que subsidiaram genocídios.

$\mathrm{Na}$ América, a ideia de raça foi uma maneira de outorgar legitimidade às relações de dominação. Historicamente, isso significou uma nova maneira de legitimar as antigas ideias e práticas de relações de superioridade/inferioridade entre dominantes e dominados. 
Desde então demonstrou ser o mais eficaz e durável instrumento de dominação social universal, pois dele passou a depender outro igualmente universal, no entanto mais antigo, o intersexual ou de gênero: os povos conquistados e dominados foram postos numa situação natural de inferioridade, e consequentemente também seus traços fenotípicos, bem como suas descobertas mentais e culturais. Desse modo, raça converteu-se no primeiro critério fundamental para a distribuição da população mundial nos níveis, lugares e papeis na estrutura de poder da nova sociedade. Em outras palavras, no modo básico de classificação social universal da população mundial (QUIJANO, 2005, p. 107).

Por consequência dessa divisão maniqueísta de mundo, a conclusão lógica é a desumanização do sujeito colonizado, juntamente com a profunda desigualdade econômica do contexto colonial e as enormes disparidades dos estilos de vida que evidenciam a realidade (des)humana existente. Os colonizadores retiram à força o valor mais essencial para o povo colonizado, que é a sua terra, através da qual poderia sobreviver (STREVA, 2015, p. 8).

Eu compreendo a hierarquia dicotômica entre o humano e o não humano como a dicotomia central da modernidade colonial. Começando com a colonização das Américas e do Caribe, uma distinção dicotômica, hierárquica entre humano e não humano foi imposta sobre os/as colonizados/as a serviço do homem ocidental. Ela veio acompanhada por outras distinções hierárquicas dicotômicas, incluindo aquela entre homens e mulheres. Essa distinção tornou-se a marca do humano e a marca da civilização. Só os civilizados são homens ou mulheres. Os povos indígenas das Américas e os/as africanos/as escravizados/ as eram classificados/as como espécies não humanas - como animais, incontrolavelmente sexuais e selvagens. O homem europeu, burguês, colonial moderno tornou-se um sujeito/ agente, apto a decidir, para a vida pública e o governo, um ser de civilização, heterossexual, cristão, um ser de mente e razão (LUGONES, 2014, p.936).

As clivagens e genocídios produzidas pela ordem moderna-colonial-capitalista de fato se sofisticaram no sentido de produzir variados tipos de genocídios e violências.

A construção das hierarquias raciais, de gênero e de modos de apropriação dos recursos naturais, pode ser vista como simultânea e contemporânea à constituição de uma divisão internacional do trabalho e dos territórios, marcada por relações assimétricas entre economias cêntricas e periféricas. Na perspectiva da colonialidade, as antigas hierarquias coloniais, que foram agrupadas na relação europeu versus não europeu, continuaram arraigadas e enredadas na divisão internacional do trabalho e na acumulação do capital à escala global. O mesmo poderia ser dito do estabelecimento de relações sociais cujo modo operativo favorece tanto a constituição quanto a perpetuação da existência de sujeitos subalternizados nas esferas intra e interestatais (ASSIS, 2014, p. 614).

As desigualdades e violências que assolam o mundo a partir da matriz colonial-capitalista evidenciam: sobre a colonização não se ergue civilização, mas sim barbárie (RUFINO, 2019). O processo civilizatório se produziu na validação desde os ataques, saques, evangelizações e genocídios promovidos no período de formação de colônias por países Europeus em nome da civilização, até a validação de construção e cidades com apartheids tornados naturais e necessários à ordem social, como na cidade do Rio de Janeiro - onde este texto é produzido - mas também em tantas outras cidades e nos inteiores de um país tão grande como o Brasil. O projeto colonial segue atualizando seu operar garantindo ordens mundiais de dominação históricas e seculares, como as que são e foram submetidos os países de América do Sul.

A normatização do mundo em um esquema binário é mais uma marafunda colonial, considerando que a própria Europa nunca foi versada em uma única banda. Assim, ressalto que, quando lanço minha crítica a modernidade, faço sobre aquilo que o seu projeto de 
dominação colonial reivindica ser. Ou seja, a mentira propagada por séculos envolta num véu de pureza que dissumula o caráter devastador, legitimado a partir de intervenção do outro como parte a ser dominada para a ascensão da civilização. Eis que se ergue o que chamo de marafunda, assombro e carrego colonial (RUFINO, 2019, p. 17).

Para este texto é fundamental a compreensão acerca dos processos de atribuição de categorias de desumanização a povos colonizados. Apostamos neste entendimento para compreender as formas de produção das profundas desigualdades no Brasil contemporâneo. É fundamental também a compreensão de que tais modos de diferenciação social são parte estruturante de uma ordem social de exploração capitalista que se expressa em profundas desigualdades raciais, de renda e de gênero, até a negação do direito à vida, exposição ao sofrimento de violências, precariedade de acesso a serviços de saúde e condições pré-determinadas de sofrimento psíquico, por exemplo.

É fundamental o esforço de compreensão sobre como a estrutura moderna-colonial-capitalista produziu e reproduz secularmente desigualdades sociais profundas a partir da noção de racialidade e estruturação global do capitalismo, tendo por base processos de subjetivação, envolvendo valores sobre quem é mais ou menos humano, subsidiando ao fim e ao cabo, todo um ordenamento social de genocídio e cisões seculares.

\title{
A branquitude no centro do projeto moderno-colonial
}

Por branquitude entende-se o constructo ideológico de poder que se produz nos processos históricos de colonização, no qual brancos tomam sua identidade racial como norma e padrão e, dessa forma, outros grupos aparecem ora como margem, ora como desviantes e ora como inferiores (SCHUCMAN, 2012).

\begin{abstract}
A branquitude é um constructo ideológico no qual o branco se vê e classifica os não brancos a partir do seu ponto de vista. Ela implica vantagens materiais e simbólicas aos brancos em detrimento dos não brancos. Tais vantagens são fruto de uma desigual distribuição de poder (político econômico e social) e de bens materiais e simbólicos. Ela apresenta-se como norma, ao mesmo tempo em que como identidade neutra, tendo a prerrogativa de fazer-se presente na consciência do seu portador, quando é conveniente, isto é, quando o que está em jogo é perda de vantagens ou privilégios (SILVA, 2017, p. 27-28).
\end{abstract}

Bento (2002), aponta o teor narcísico no processo de produção do "outro" destituído de humanidade pelo homem branco europeu, já apontado neste texto. Cita a construção Freudiana do narcisismo para falar sobre a aversão daquilo que é considerado o diferente de si, e sobre como este "estranho" ou "diferente" colocam em questão o dito "normal", surgindo assim uma necessidade de autopreservação a partir da aversão ao "outro". A autora cita ainda o processo de "falsa-projeção como o mecanismo por meio do qual o sujeito procura livrar-se dos impulsos que ele não admite como seus, depositando-os no outro" (BENTO, 2002, p. 38), e que por meio deste tipo de mecanismo "os sujeitos perdem a capacidade de discernir entre o que é deles e o que é alheio, e tudo vira falsa-projeção, exterioridade" (BENTO, 2002, p. 38). Ao projetar os impulsos, o sujeito consegue se livrar deles e, ao mesmo tempo, reagir a eles como algo pertencente ao mundo exterior. O processo resulta em um tipo de paranoia que caracteriza frequentemente quem está no poder e tem medo de perder seus privilégios.

As análises apontam a construção de um pacto narcisístico por parte dos brancos que compreende negação de seu papel social histórico, e consequentemente privilégios, com a finalidade da manutenção destes últimos. Este medo em perder seus privilégios e a incapacidade de se responsabilizar pelas desigualdades raciais desagua na projeção de características negativas fictícias do branco sobre o negro. Nesta perspectiva a autora explica ainda como as pessoas negras são retratadas por brancos na história junto a imagens demoníacas, agressivas etc (BENTO, 2002). 
Bento (2002) enfatiza a necessidade da criação do medo deste "outro", destituído de humanidade, como base para a construção dos processos psíquicos que cita. Ressalta ainda que, com relação ao medo produzido por este "outro", há uma "coincidência cronológica entre a grande caça às feiticeiras que ensanguentou o Velho Mundo, a batalha contra a peste e a luta sem trégua conduzida além do Atlântico contra negros e índios considerados como "pagãos" (BENTO, 2002, p. 34). "As explosões periódicas de medo acompanham a história europeia do final do século XIII ao começo da era industrial” (BENTO, 2002, p. 35). Assim, a autora aponta que "o medo e a projeção podem estar na gênese dos processos de estigmatização de grupos que visam legitimar a perpetuação das desigualdades, a elaboração de políticas institucionais de exclusão e até de genocídio" (BENTO, 2002, p. 35).

A projeção de sentido negativo e produção de medo acerca do "outro" pelo branco, se deu pari passu a estratégias de normalização de si mesmo, ou seja, estratégias de construção "do branco como norma". O branco produziu ao longo da colonialidade, discursos apagadores da estruturalidade do racismo e de invisibilização dos privilégios do branco na sociedade, por exemplo. No Brasil, o mito da democracia racial expressa esta desastrosa construção de sentido.

Segundo Bento (2002), o operar da branquitude exige um pacto de silêncio de forma que o "mundo branco" dado como natural e norma, apesar de desigual e assassino, não seja denunciado. Ela conceitua tal processo como o "pacto narcísico da branquitude".

O pacto prevê que o mundo ordenado pelo privilégio branco não seja incomodado com apontamentos a respeito de seu funcionamento. Assim, tentativas de acusações à estrutura racializada são facilmente recebidas por brancos como "ofensas", "como violência", como a produção de incômodo ou algo que o valha. A jogada mais eficaz aqui é inverter o sentido da violência, passar para o violentado a responsabilidade por estar "causando um incômodo".

Estas práticas, apesar de aqui estarem sendo enunciadas a partir de uma observação limitada a poucos, tem sido reproduzida em muitos lugares historicamente. E desta maneira, o sujeito branco tem cinicamente se apagado da sua responsabilidade na produção, execução e reprodução do racismo. Ou seja, este sujeito histórico produz o conceito de "raça" para retirar a humanidade do "outro" e depois se retira de sua culpabilização por este processo, negando a centralidade do racismo na matriz moderno-colonial-capitalista e retirando a centralidade do debate racial que é então apontado como algo "não importante o suficiente" ou como uma mera pauta identitária resumida ao "preconceito", como se os próprios brancos não tivessem "nada com isso". Assim, o branco se retira do problema que ele mesmo criou. Não se vê racializado, afinal, de acordo com esta ordem, o branco não é raça, mas o universal normativo, e o problema do racismo é um problema limitado aos povos negros e indíginas, não àqueles que o produziram e produzem.

Bento (2002) aponta a construção psíquica da projeção no outro daquilo que lhe é insuportável, e para o sujeito branco o processo de projetar da sua violência no sujeito negro a partir da denúncia que este faz da branquitude tem se revelado como mecanismo para se esquivar do lugar de violentador. Acontece que não há forma de escamotear tal fato. Ao produzir este discurso, o sujeito branco revela a si mesmo sua tentativa de fuga de seu papel e/ou seu cinismo.

Aqui se revela a manutenção do pacto da branquitude por meio de silenciamentos produzidos pelos brancos como reação a uma acusação de racismo a partir da fuga de sua responsabilidade. Assim, a branquitude investe para que práticas de manutenção dos privilégios brancos se dêem de maneira pretensamente velada, para que o sujeito branco goze suas vantagens sem o incômodo de sentir-se responsável ou culpado pelas desigualdades produzidas pelo racismo.

Ao invés de reações sustentadoras do operar da branquitude e da matriz de colonialidade, sujeitos brancos devem responsabilizar-se pelo operar da racialidade e produzir maneiras de falar sobre o operar da branquitude e acerca desta matriz. Assim, nos parece fundamental o investimento em ações de quebra do pacto do silêncio da branquitude. 
Nesse sentido, é importante, ao analisar a branquitude, refazer essa história,considerando a forma como essas narrativas históricas são construídas, refletindo sobre as estratégias de manutenção dos privilégios dessa elite pós-colonial branca e identificando novas maneiras de identificação racial dos sujeitos brancos. Outro ponto fundamental é indagar que tipo de branquitude vem se construindo na sociedade brasileira e como a mesma se relaciona com os processos de produção do conhecimento (LABORNE,2014, p.159).

O racismo é uma ferida que não se cura soprando, é preciso tocar nela profundamente. E isto dói. Sempre houve dor pro sujeito negro. Não pode ser mortal o desconforto e a dor no sujeito branco. Mas a branquitude é um "tumor" que deve ser socialmente extraído, junto com o racismo. Não haverá fim do racismo sem o fim da branquitude. Aviso, mesmo não achando necessário: fim da branquitude não tem nada a ver com fim das pessoas brancas. Tá dito. A branquitude é um tumor no corpo social porque, entre outras razões, no seu predomínio por séculos e séculos, a branquitude (sobretudo os produtores brancos de saber) perderam a noção de privilégios que sempre possuíram ou sabem que estes privilégios perceptivelmente existem mas insistem em dissimula-lo, negando sua existência total (PACHECO, 2017).

Priscilla (FERREIRA, 2020) reafirma que ao (tentar) desumanizar o "outro", o branco fala de si mesmo e não de fato a respeito do "outro". Projeta sua violência, inseguranças, ansiedades, ou seja, sua miséria existencial naquele que tenta racializar. O branco despeja no "outro" aquilo que não quer assumir, nem reconhecer, nem se auto-responsabilizar.

Enquanto não se auto responsabilizar pelos desafios e falhas da sua condição de humanidade, a branquitude, como identidade racial, continuará carente a extrair a autonomia e plenitude alheia, sem dar conta de sua própria existência material, cognitiva, subjetiva, espiritual, terceirizando os esforços, sacrifícios e trabalho exigidos para sobreviver e se desenvolver.

Não adianta tentar grilar o solo da existência alheia, isso não faz de um ser humano dono de si. Ao contrário, lhe desumaniza em retorno, rebaixa sua existência a de um parasita.

Homens e mulheres branc@s, assumam suas fragilidades, erros, dores, privilégios e o esforço do trabalho concreto e afetivo que exige a recuperação da sua própria humanidade despedaçada e debilitada, que séculos de desumanização de negros/as e indígenas lhes custou e custará aos seus herdeir@ (FERREIRA, 2020,p. 1).

\section{Enfrentando e fazendo falar o pacto narcísico da branquitude}

Apotamos até agora algumas pistas sobre como a branquitude se constrói e se retualiza através da história para a manutenção de privilégios mateiais e subjetivos. A contínua construção de estrtatégias de naturalização dos privilégios brancos tem sido diversa e dissimulada, por meio do entendimento do branco como a norma.

Nomear a norma é o primeiro passo rumo a uma redistribuição desobediente de gênero e anticolonial da violência, porque a norma é o que não se nomeia, e nisso consiste seu privilégio. A não-marcação é o que garante às posições privilegiadas (normativas) seu princípio de não questionamento, isto é: seu conforto ontológico, sua habilidade de perceber a si como norma e ao mundo como espelho. Em oposição a isso, "o outro" - diagrama de imagens de alteridade que conformam as margens dos projetos identitários dos "sujeitos normais" - é hiper- marcado, incessantemente traduzido pelas analíticas do poder e da racialidade, simultaneamente invisível como sujeito e exposto enquanto objeto. Nomear 
a norma é devolver essa interpelação e obrigar o normal a confrontar-se consigo próprio, expor os regimes que o sustentam, bagunçar a lógica de seu privilégio,intensificar suas crises e desmontar sua ontologia dominante e controladora (MOMBAÇA, 2016, p. 11).

Convocamos autoras, autores, marcos históricos e diversas formas de explicação para falar da produção do "outro" na colonialidade e processo de estruturação e inviabilização, mas a violência da colonialidade e os traumas por ela provocados são, em parte, indizíveis, e ultrapassam a capacidade racional de explicar (KILOMBA, 2019). O desvelar dos mitos da colonialidade, no entanto, exige muitos processos de "fazer falar", como nos apontou acima, Mombaça.

Avançar no entendimento e produção de linguagem para compreender, fazer falar e quebrar os pactos de silêncio que sustentam os mitos da modernidade-colonialidade. "Falar sobre, suportar e tornar a inquietação colonial que nos constitui em algo produtivo. Consideramos que torná-lo visível é fundamental para que tratemos da reparação e da recuperação política e afetiva que suscita" (GONÇALVES et al., 2019, p. 162).

As possibilidades para uma sociedade menos marcada por desigualdades passa necessariamente por um debate mais profundo sobre branquitude e sobre o branco como raça. Promover tensões no pacto narcísico e expor o medo constante da exposição da subjetividade branca. Um passo adiante possível é não só demarcar os privilégios herdados pelos brancos, mas como os mesmos são construídos e quanto são mantidos. Maria Aparecida Bento, já citada neste texto, aponta que ao falar deste assunto precisamos enunciar que falamos sobre credores e devedores na história. E como esta mesma autora já nos elucidou, para o branco, não há como esquivar-se desta constatação sem denunciar a si mesmo.

É necessário reconhecer o papel do corpo branco, não apenas como fenótipo, mas principalmente, pelo valor social que é produzido e o que é tirado como proveito dele. Demonstrar que os privilégios materiais e simbólicos da branquitude passam necessariamente por um conjunto de ações que se reproduzem materialmente, subjetivo-simbólicamente e historicamente. Como já apontado, tais privilégios estão presentes hoje na divisão racial do trabalho, na criminalização e genocídio dos moradores de favelas e periferias do país, nas tentativas frequentes de grupos brancos visando impedimento da efetivação das ações afirmativas, na formação educacional que conta majoritariamente com currículos brancos e eurocentrados, na aceitação da destribuição racial desigual dos padrões de vida, adocimento e morte. Ressalta-se ainda toda a construção subjetiva e simbólica que sustenta todo este arcabouço de poder branco, localizado no nível do nosso inconsciente, colonizando nossos desejos, enunciando o belo, o inteligente, o capaz, ou seja, tudo que é positivo, como aquilo que é de referência branca.

Para promover tensões ao pacto, é preciso enfrentar o medo que acompanha a branquitude e todo seu processo de construção social e subjetivo. Se apresentar como raça e protagonista de um modelo de sociedade de base genocida e construído a partir de tentativas de destruição da imagem e do corpo do que enunciou como "outro". Assumir-se como devedor e de ancestralidade assassina. Tal tensão será produzida a partir da contradição da invisibilidade defendida pela branquitude, que se vê como universal, que se julga sem lugar de fala, como se não fosse responsável pelo apartheid racial secular. Afinal de contas essa invisibilidade da própria raça cai por terra quando ridiculamente um branco reivindica racismo reverso. A ameaça do seu lugar frente ao modelo universal demonstra a fragilidade e o cinismo que acompanha a branquitude a séculos na construção social desse país.

\section{o pacto branco na invisibilização das características populacionais}

O estudo dos padrões de saúde e adoecimento das populações é objeto histórico de interesse do campo da saúde pública, e no Brasil, também da Saúde Coletiva. Esta área de estudo expressa sua relevância 
principalmente no que tange seu potencial na produção de indicadores de saúde, evidências e propostas para o direcionamento de políticas públicas de saúde, medidas para o controle de doenças etc. Ressaltamos, entretanto, que a forma como se compreende o processo saúde-adoecimento muda radicalmente dependendo da filiação ética, política e teórica que se utiliza. A perspectiva do modelo biomédico vem reforçando historicamente o biologicismo, a perspectiva histórica e individualista (MENÉNDEZ, 2005). Compreensão reforçada nos séculos XIX e XX com a construção do campo da saúde pública a partir da polícia médica e/ ou de higiene com base na ideia de que a saúde da coletividade é a soma dos quadros de saúde individuais, entendimento que subsidia ações centradas em controle do adoecimento a partir da perspectiva dos fatores de risco. Um entendimento funcionalista da sociedade, de que é possível alterar pontualmente suas "engrenagens" de funcionamento.

Esta perspectiva contribui para uma compreensão reducionista do processo saúde-doença, e mais, a sua pretensa (a)historicidade provoca uma anulação do entendimento de que tais processos podem ser compreendidos a partir de sua determinação histórica e social. Quando analisamos os padrões de vida, adoecimento e morte, as desigualdades escancaram os marcadores de raça, classe e gênero presentes na estrutura social, por exemplo. E tais marcadores foram e são produzidos historicamente e não fruto do acaso. A naturalização das desigualdades presentes nestes padrões sustenta um silêncio mantenedor dela mesma. Ao estudar as condições de saúde da população brasileira, por exemplo, como fazemos a leitura de tais dados? Como temos desenhado as políticas de saúde ofertadas a população?

De acordo com dados do CENSO (IBGE, 2010), o Brasil possui 191 milhões de habitantes, conta com 97 milhões de negros, o equivalente a 51\%. No entanto, na cidade do Rio de Janeiro, por exemplo, a inclusão da informação "raça" passou a ser obrigatória em todos os formulários de saúde no município por meio da lei número 4.930 de 22 de outubro de 2008 (RIO DE JANEIRO, 2008). Apesar de a PNSIPN² (fruto de intesa mobilização do movimento negro brasileiro) já ter onze anos de publicação e a introdução do quesito raça cor nos Sistemas de Informação de Mortalidade, de Nascidos Vivos e de Notificação de Agravos tenha vinte e três anos, somente em 2017 que o preenchimento desse campo se tornou obrigatório em todo o país em todos os sistemas de informações do SUS, por meio da Portaria número 344 de $1^{\circ}$ de fevereiro de 2017. Notamos que esta conjuntura acerca do quesito raça/cor reflete o apagamento a respeito da importância de se compreender como raça atravessa as características populacionais no que tange seus padrões de adoecimento.

Assim, perguntamos: ao produzir as políticas de saúde consideramos as marcas de desigualdades estruturantes do capitalismo-colonialidade como as raciais, de classe e gênero? Ou desenhamos ainda políticas de saúde que ignoram esses marcadores e nossos traumas da colonialidade? Acreditamos que o pacto de silêncio da branquitude se expressa, também, na saúde, quando estudamos processos de saúde-adoecimento sem considerar as marcas das desigualdades raciais da população brasileira. Abaixo trazemos alguns elementos que nos ajudam a compreender esta hipótese.

\section{o pacto de silêncio refletido na elaboração de políticas de saúde: o exemplo da hipertensão arterial sistêmica}

O pacto narcísico da branquitude opera e se reproduz seja nas suas formas privadas ou públicas. Fica evidente que tal pacto colabora para o que Achille Mbembe (MBEMBE, 2018) define como necropolítica, ou seja, os corpos marcados para morrer do ponto de vista deste Estado burguês que se apresenta a partir de uma suposta igualdade universal dos direitos, mas discrimina e exacerba os marcadores sociais como raça, classe e gênero. Do ponto de vista da saúde, cabe destacar que essa estrutura opera desde a construção de políticas até a prática nos serviços, a partir da reprodução e produção de reflexos do processo de invisibilidade do "outro" racializado pelos brancos.

2 Política Nacional de Saúde Integral da População Negra (PNSIPN) que reconhece o racismo como determinante social das condições de saúde da população negra. 
No Brasil, somente no século XXI foi desenvolvida uma Política Nacional de Saúde Integral da População Negra (2009), fruto de esforço e articulação dos movimentos negros, mas que até hoje enfrenta-se um conjunto de desafios para implementação (NETO et al., 2015) colocados pela ordem racista brasileira. Uma busca recente, voltada para uma pesquisa em desenvolvimento sobre acesso a medicamentos no Brasil pela população negra demonstrou que há uma escassez de estudos nessa área, e ainda, uma informação bastante relevante que envolve este assunto. Correia e colaboradores (2019) demonstraram que a população negra apresenta notória prevalência para doenças relacionadas à hipertensão arterial comparada quando comparada com brancos, e para agravar esse quadro, a resposta para o tratamento com inibidores da Enzima Conversora de Angiotensina (iECA) é menos eficaz (VARGAS; CARDOSO, 2016).

Porém, mesmo a par dessas informações preocupantes e relevantes encontramos em documentos do Ministério da Saúde, voltados para o tratamento da hipertensão no Brasil, publicado em 2006 e atualizados em 2010 e 2013, as seguintes passagens no texto:

Nos negros, a prevalência e a gravidade da hipertensão são maiores, o que pode estar relacionado a fatores étnicos e/ou socioeconômicos. Em nosso país predominam os miscigenados, que podem diferir dos negros quanto às características da hipertensão. Não há evidências de ação diferenciada das drogas anti-hipertensiva em nossa população. Entretanto, estudos recentes em populações de indivíduos negros norte-americanos, o uso de iECA se mostraram menos eficazes, especialmente na prevenção de AVC, que outras classes de anti-hipertensivos. Devendo, portanto, não serem considerados de primeira escolha nesta população" (BRASIL, 2006, p. 33).

Na população negra, a prevalência e a gravidade da hipertensão é maior, o que pode estar relacionado a fatores étnicos e/ou socioeconômicos. Em nosso País, predomina a população miscigenada, que pode diferir da população negra quanto às características da hipertensão. Desta forma, para pacientes negros, desde que não haja contraindicações, o uso de diuréticos e bloqueadores de canais de cálcio é a opção mais racional" (BRASIL, 2013 p. 60).

Embora a forma atualizada do documento traga uma alternativa ao tratamento que não os iECA, ambas as passagens grifadas podem ser correlacionadas, primeiro, com a obra "A redenção de Cam" de Modesto Brocos, pela necessidade de forçar o embranquecimento da população brasileira, ao assumir o discurso da miscigenação e afirmar que não há população negra no Brasil. Em segundo, a necropolítica do Estado brasileiro, que negligencia a população negra que não apresenta uma resposta eficaz comprovada para a classe de hipertensivos mais prescrita e dispensada pelo SUS; ao mesmo tempo que é a população negra a maior usuária do Sistema Único de Saúde.

Aqui fazemos apontamentos ao SUS pois é este um marco ético político no Brasil, que, ao enunciar saúde como direito de todos, produz tensão na colonialidade-capitalista à brasileira, situando saúde como um direito humano básico e não como uma mercadoria, engendrada a lógica do capital. As disputas, no entanto, devem se produzir no sentido da construção de um sistema de saúde público, cada vez mais fortalecido, que não compreenda a população brasileira como homogênea, mas marcada por desigualdades estruturantes, e que, por consequência, produza e execute políticas de saúde que respondam às características de desigualdades em saúde presentes no Brasil, como as produzidas pelo racismo.

O trecho da citação direta acima, no parágrafo "Na população negra, a prevalência e a gravidade da hipertensão é maior, o que pode estar relacionado a fatores étnicos e/ou socioeconômicos", põe em dúvida uma assertiva a respeito da determinação social da saúde: que populações historicamente submetidas a piores condições de vida irão expressar, por consequência, formas mais severas de adoecimento. Percebemos que a negação da determinação social da saúde que inclui como os marcadores sociais da diferença constituem os processos de adoecimento vem sendo forjada dentro da própria área da saúde. O que contraria uma 
possibilidade de compreensão ampla a respeito das condições de saúde populacionais, como por exemplo, o entendimento acerca do quadro de transição epidemiológica - que inclui o avanço dos casos de HAS - que se situe em história e em marcas sociais, e que por isso, não atinge/adoece igualmente a população, mas sim de forma mais desigual e mais cruel para uns que para outras e outros.

A exemplo das diferenciações produzidas neste contexto, ainda sobre a HAS, Nadruz (ALVES FILHO, 2017) reafirma que a literatura médica tem registrado que pessoas negras têm apresentado níveis de pressão arterial mais altos e têm maior dificuldade para controlá-los, ressalta que apesar desta constatação não há evidência no campo da fisiologia/biologia para tal. Assim, aponta a determinação das condições socioeconômicas para o desenho deste quadro. Em estudo desenvolvido pela (UNICAMP) em parceria com a Harvard Medical School, do qual Nadruz participou, revelou-se que, apesar de alguns avanços relacionados ao acesso ao tratamento para a HAS terem direcionado a uma diminuição dos AVCs por HAS nos últimos 20 anos, essa diminuição afetou mais os brancos que os negros (ALVES FILHO, 2017). Aqui se aponta a cascata de morte produzida pela necropolítica. Quando todo processo histórico de vulnerabilização deságua num quadro de AVC evitável, quadro que sabemos, pode levar a sequelas irreversíveis, e que pode, por consequência, mobilizar toda uma estrutura de cuidados familiares dada a ausência de pleno acesso aos direitos de cuidado e assistência. Para além, evidentemente, da perda potencial de vida (ou de qualidade dela) da pessoa acometida pelo AVC e a perda social que isso reflete, denunciando a falência societária imposta por essa ordem colonial racista.

Reiteramos que a PNSIPN tem como marca "o reconhecimento do racismo, das desigualdades étnico-raciais e do racismo institucional como determinantes sociais das condições de saúde, com vistas à promoção da equidade em saúde" (BRASIL, 2009,p.26) e como objetivo geral "promover a saúde integral da população negra, priorizando a redução das desigualdades étnico-raciais, o combate ao racismo e à discriminação nas instituições e serviços do SUS" (BRASIL, 2009, p. 27). Reconhecer o racismo estrutural para então agir no seu combate, como proposto pela PNSIPN parece exigir quebras dos pactos de silêncio da branquitude dentro do setor saúde, seja no serviço, na gestão, na formulação de políticas públicas ou nos processos de formação.

A HAS parece ser um alerta para a determinação social da saúde, uma expressão detectável e grave do longo processo histórico de imposição de desigualdades, ausência de direitos e violências. A PNSIPN aponta a necessidade da identificação das necessidades de saúde da população negra, para que sirva como critério de planejamento e definição de prioridades (BRASIL, 2009). E percebemos que mesmo quando temos dados que apontam, desde a necessidade de diretriz farmacológica mais precisa, até a compreensão de um maior adoecimento e maior produção de sequelas para esta (maior) porção da população, há silenciamento quanto a estes conhecimentos, reforçando uma invisibilização que mantém essa população submetida a baixa qualidade de cuidado em saúde e sendo tratada a partir dos parâmetros da população-norma: a branca. E assim a necropolítica se reproduz e reatualiza.

O enfrentamento ao pacto também envolve desvelar essa estrutura, e expor o quanto racismo está instituído na sociedade brasileira. A reatualização do operar genocida no Brasil não se dá apenas na violência imposta pelo Estados nas favelas e periferias do país, mas também nas práticas e políticas de saúde quando ignoram as especificidades e respostas aos tratamentos farmacológicos disponibilizados. Pensar saúde e acesso a medicamentos para a população negra é uma dívida e uma necessidade urgente.

\section{0 pacto de silêncio na formação acadêmica}

Parte do problema e reafirmação do pacto do silêncio se dá ainda na formação dos profissionais na área da saúde. Souza (2019) evidencia que o caráter racista e sexista da Saúde Coletiva se desvela ainda na pós-graduação, com silenciamentos, apagamentos de intelectuais negros nas bibliografias e a constante opressão e tentativa de violação das temáticas de pesquisa que trabalhem a população negra, quando escrita por corpos pretos. Esses são comumente rechaçados e normalmente descontinuados (SOUZA, 2019). 
A produção de conhecimento legitimada é aquela produzida pelo homem-branco-intelectual e a ele se dá também o poder de ditar o que é legítimidade. Desse modo torna-se factível e aceitável, por exemplo, ter em documentos do Ministério da Saúde a afirmação de que não temos predominância negra no Brasil por se tratar de um país miscigenado e usar desse discurso para não buscar alternativas que sejam, de fato, eficazes à saúde da população negra, ficando essa mais uma vez preterida.

É importante salientar que no final do século XIX, diversos intelectuais brasileiros da saúde compreendiam que a eugenia seria a forma de construir uma nova identidade nacional, acabando com o atraso civilizacional através da miscigenação. Calcavam-se nas teorias pseudocientíficas e no preconceito racial ditados por intelectuais europeus. A Eugenia brasileira se aproximou e relacionou como um ramo da higiene, andando de braços dados com o sanitarismo e é possível observar seus resquícios ainda hoje nas instituições formadoras e produtoras de conhecimento. É também no âmbito da saúde brasileira que intelectuais se mobilizam e produzem conhecimento crítico em saúde abarcando, por exemplo, a determinação social da saúde e a epidemiologia crítica. Somos compostos por contradições inscritas em nossa história e precisamos estar atentos aos possíveis silenciamentos que produzimos.

Apesar dos valorozos esforços já produzidos no que tange a ampliação do acesso ao ensino universitário, temos ainda universidades majoritariamente compostas por pessoas brancas, com currículos, docentes, discentes e história calcadas na branquitude. Espaços que continuam produzindo conhecimento que, em muito, reafirmam os pactos de silêncio, como afirma Souza:

É a imparcialidade do sujeito que se entende como universal. Ou seja, para que a visão de mundo do homem branco europeu se torne hegemônica, cria-se o mito de que o conhecimento somente é possível de ser construído a partir da objetividade científica e, para isso, nega-se o lugar de fala dos indivíduos pesquisados, ou lhe é negada a prerrogativa de sujeito potencialmente capaz de produzir conhecimento" (SOUZA, 2019, p. 197).

É comum depararmo-nos com indagações da branquitude questionando seu papel e reivindicando um não-lugar de fala nas questões raciais como já mencionamos aqui anteriormente, mas é necessário que esse se veja como branco racializado e responsável por ações de reparação, colocando-se na luta pela descolonização do pensamento, das ações e das teorias.

Discutimos pouco, no campo da saúde no Brasil, como preservamos ainda traços, discursos e ações de seu nascimento conjunto com o eugenismo e higienismo que no Brasil foram operados por meio de instituições de saúde. Nossa história, calcada na operação direta da matriz colonial, parece ser de alguma forma escamoteada e relacionada de forma mais evidenciada com a medicina social europeia (FOUCAULT, 2000; VIERA-DA-SILVA, 2018). Decerto que há contradições e história densa no que tange a construção do campo no Brasil, abrangendo filiações diversas, no entanto, vale perguntar: porque não falamos costumeiramente sobre as faces mais nefastas de nossa história?

A tarefa histórica da enunciação de si como sustentação de uma estrutura social de mortes e desigualdades: uma tarefa da branquitude. Há necessidade em falar e agir sobre a estrutura histórica de produção de mortes e desigualdades, esmiuçar como as práticas de hegemonia e poder da branquitude se reatualizam atualmente, operando pretensamente na naturalidade-invisibilidade. Em nossas insituições e institucionalidades todo lugar é passível de quebra dos pactos de silêncio da branquitude, pois ao que tudo indica, eles constituem as bases institucionais. Avante!

\section{Referências}

ALVES FILHO, M. Hipertensão é mais persistente entre negros, aponta estudo. Jornal da Unicamp. Campinas, 2017. Disponível em: <https://www.unicamp.br/unicamp/ju/noticias/2017/07/13/hipertensao-e-maispersistente-entre-negros-aponta-estudo>. Acesso em 13 jul. de 2020. 
ASSIS, Wendell Ficher Teixeira. Do colonialismo à colonialidade: expropriação territorial na periferia do capitalismo. Cad. CRH, Salvador, v. 27, n. 72, 613-627, 2014.

BALLESTRIN, Luciana. América Latina e o giro decolonial. Revista brasileira de ciência política, vol. 11, 2013 , p. 89. BARTHES, R. Mitologias. $11^{\text {a }}$ ed. Rio de Janeiro, Bertrand, 2001.

BENTO, Maria Aparecida Silva. Branqueamento e branquitude no Brasil. In: CARONE, Iray; BENTO Maria Aparecida Silva (Org.). Psicologia social do racismo: estudos sobre branquitude e branqueamento no Brasil. Rio de Janeiro: Vozes, 5-58, 2002.

BRASIL. Ministério da Saúde. Secretaria de Atenção à Saúde. Departamento de Atenção Básica. Cadernos de Atenção Básica 15: hipertensão arterial sistêmica para o Sistema Único de Saúde. Brasília, DF, 2006.

BRASIL. Ministério da Saúde. Secretaria de Atenção à Saúde. Departamento de Atenção Básica. Estratégias para o cuidado da pessoa com doença crônica: hipertensão arterial sistêmica. Brasília, DF, 2013.

BRASIL. Portaria no 992, de 13 de maio de 2009. Institui a Política Nacional de Saúde Integral da População Negra. Brasília, DF, 2009.

CORREIA, Rafaela R. et al. Hipertensão arterial na etnia negra: uma revisão da terapia medicamentosa. Brazilian Journal of Surgery and Clinical Research - BJSCR. Vol.27, n.1, 2019, p. 157-159.

DUSSEL, Enrique. M. Filosofia da Libertação: crítica à ideologia da exclusão. MAISSIAT, George I. (Trad.). São Paulo: Paulus, 1995.

FANON, Frantz. Os condenados da terra. 2a ${ }^{\text {a }}$ Ed, Rio de Janeiro: Civilização Brasileira, 1979.

FANON, Frantz. Pele negra, máscaras brancas. Salvador: EdUfba, 2008.

FBSP. Fórum Brasileiro de Segurança Pública. Nota técnica: Violência doméstica durante a pandemia de Covid-19, 2020. Disponível em: <https://forumseguranca.org.br/wp-content/uploads/2018/05/violencia-domestica-covid-19-v3. pdf $>$. Acesso em 15 jun, 2021.

FERREIRA, Priscilla. Policiamentos da caixa de pandora da branquitude. Iniciativa direito a memória e justiça racial. Rio de Janeiro, 2020. Diposnível em<https://dmjracial.com/2020/07/28/policiamentos-da-caixa-de-pandora-da-branquitude/> Acesso em 01/08/2020.

FOUCAULT, Michel. Em defesa da sociedade. Curso no Collège de France (1975-1976), 2000.

FRANCO, Anielle et al. Por que a fila única é a saída para salvar vidas? Perifa Connection, Folha de São Paulo, 4 de junho de 2020. Disponível em: <https:/www1.folha.uol.com.br/colunas/perifaconnection/2020/06/por-que-a-fila-unica-ea-saida-para-salvar-vidas.shtml> Anexo em: 19 abr 2021.

GONÇALVES, L.A.P.; OLIVEIRA, R.G.; GADELHA, A.G.S.; MEDEIROS, T.M. Saúde coletiva, colonialidade e subalternidades-uma (não) agenda? Saúde em Debate, vol. 43, 2019, p. 160-174.

GROSFOGUEL, Ramón. Para descolonizar os estudos de economia política e os estudos pós-coloniais: transmodernidade, pensamento de fronteira e colonialidade global. Revista crítica de ciências sociais, n. 80, 2008, p. 115-147.

HALL, Stuart. Raça, o significante flutuante. Revista Z Cultural, 2013.

IBGE. Instituto Brasileiro de Geografia e Estatística. Censo Demográfico, 2010. Disponível em <www.ibge.gov.br> Acesso em 04 jul. de 2020 .

IBGE. Instituto Brasileiro de Geografia e Estatística. Diretoria de Pesquisas. Coordenação de População e Indicadores Sociais. Estudos e análises, Informação Demográfica e Socioeconômica, n. 2.- Rio de Janeiro, 13-29, 2013.

KILOMBA, Grada. Grada Kilomba: desobediências poéticas. Curadoria Jochen Volz e Valéria Piccoli. Pinacoteca de São Paulo. São Paulo, 2019. Disponível em: <http://pinacoteca.org.br/wpcontent/uploads/2019/07/AF06_gradakilomba_ miolo_baixa.pdf>. Acesso em 15 jun, 2021.

LABORNE, Ana A. P. Branquitude e colonialidade do saber. Revista da Associação Brasileira de Pesquisadores/as Negros/ as (ABPN), v. 6, n. 13, 2014, p. 148-161.

LUGONES, María. Rumo a um feminismo descolonial. Revista Estudos Feministas, v. 22, n. 3, 935-952, 2014.

MARINO, Aluízio; BRITO, Gisele; MENDONÇA, Pedro; ROLNIK, Raquel. Prioridade na vacinação negligencia a geografia da Covid-19 em São Paulo. Labcidade, 2021. Disponível em: <http://www.labcidade.fau.usp.br/prioridade-navacinacao-negligencia-a-geografia-da-covid-19-em-sao-paulo/?fbclid=IwAR39j-kt3MkmHNFBlcGNJelyzJ8gVxojsrJXkI 
TgAv5glYr3O-L3UJH9cW8>. Acesso em 16, jul, 2021.

MARINO, Aluízio; ROLNIK, Raquel; KLINTOWITZ, Danielle; BRITO, Gisele; MENDONÇA, Pedro; NISIDA, Victor; CAVALCANTE, Lara. Simplificaçáo da leitura do comportamento da epidemia no território dificulta seu enfrentamento. Labcidade, 2020. Disponível em: <http://www.labcidade.fau.usp.br/simplificacao-da-leitura-do-comportamento-daepidemia-no-territorio-dificulta-seu-enfrentamento/>. Acesso em 16, jul, 2021.

MATOS, Déborah D. Racismo científico: O legado das teorias bioantropológicas na estigmatização do negro como delinqüente. Âmbito Jurídico, Rio Grande, XIII, n. 74, mar 2010. Disponível em < http://www.ambitojuridico.com.br/ site/index.php?n_link=revista_artigos_leitura\&artigo _id=7448 >

MBEMBE, Achille. Necropolítica. São Paulo: n-1 ediçóes, 2018

MENDONÇA, André L.O.; GONÇALVES, Leandro A.P. 'Sobre o conceito da História’ na saúde coletiva. Saúde em debate. Rio de Janeiro. v. 43, n. especial 8, 203-215, 2019.

MENÉNDEZ, Eduardo L. El modelo médico y la salud de los trabajadores. Salud colectiva, La Plata, 2005, 1: 9-32.

MOMBAÇA, Jota. Rumo a uma distribuição desobediente de gênero e anticolonial da violência! Cadernos de Imaginaçáo Política, 2016 Disponível em: <https://issuu.com/amilcarpacker/docs/rumo_a_uma_redistribuic_a_o_da_vi> Acesso em: 26/12/2019.

MUNANGA, Kabenguele. Uma abordagem conceitual das noçóes de raça, racismo, identidade e etnia. In: BRANDÁO, A.A.P. (Org.) Programa de educação sobre o negro na sociedade brasileira. Niterói: EdUFF, 2000. p. 15-34.

NETO, José A.C. et al. Política Nacional de Saúde Integral da População Negra: implementação, conhecimento e aspectos socioeconômicos sob a perspectiva desse segmento populacional. Ciênc. saúde coletiva, vol. 20, n. 6, 2015.

OLIVEIRA, Roberta G. et al . Desigualdades raciais e a morte como horizonte: consideraçôes sobre a COVID-19 e o racismo estrutural. Cad. Saúde Pública. Vol. 6, n. 9, 2020, e00150120.

OLIVEIRA, Roberta G. Práticas de saúde em contextos de vulnerabilização e negligência de doenças, sujeitos e territórios: potencialidades e contradiçóes na atenção à saúde de pessoas em situação de rua. Saúde e Sociedade, v. 27, 2018, p. 37-50.

PACHECO, Ronilso. Coletivo Mariachi. O Fim do racismo será impossível sem o fim da branquitude. Portal Youtube 2017. Disponível em: <https://m.facebook.com/coletivomariachi/photos/a.291536030986255/910059259133926/?ty pe=3>. Acesso em: 2019 jun 2.

PETRUCCELLI, J. L. Raça, identidade, identificação: abordagem histórica conceitual. In: PETRUCCELLI, J. L.; SABOIA, A. L. (Org.). Características Étnico-raciais da População: Classificaçóes e identidades. Ministério do Planejamento, Orçamento e Gestão. Instituto de Geografia e Estatística - IBGE. Diretoria de Pesquisas. Coordenação de População e Indicadores Sociais. Estudos e análises, Informação Demográfica e Socioeconômica, n. 2.- Rio de Janeiro, 2013, p. 13-29.

QUIJANO, Anibal. Colonialidade do poder, eurocentrismo e América Latina. In: LANDER, Edgardo (org). A colonialidade do saber: eurocentrismo e ciências sociais. Perspectivas latinoamericanas. ColeccinSurSur, CLACSO, CiudadAutnoma de Buenos Aires, Argentina, 2005.

RBCE. Rede Brasileira de Cooperação em Emergências. Leitos para todos, Vidas Iguais, Rede Solidária em Defesa da Vida. Disponível em: < https://rbce.com.br/leitos-para-todos-vidas-iguais/>. Acesso em: 25 maio 2021.

REDE NOSSA SÃO PAULO. Edição extraordinária do Mapa da Desigualdade indica CEP como fator de risco na pandemia. 2020. Dispoível em: <https://www.nossasaopaulo.org.br/2020/06/24/edicao-extraordinaria-do-mapa-dadesigualdade-indica-o-endereco-como-fator-de-risco-na-pan/>. Acesso em 16 jul 2021.

RIO DE JANEIRO. Lei no 4930 de 22 de outubro de 2008. Dispóe sobre a inclusão do quesito raça nos formulários de informaçôes em saúde do Município do Rio de Janeiro e dá outras providências. Rio de Janeiro, 2008.

RUFINO, Luiz. Pedagogia das encruzilhadas. Rio de Janeiro: Mórula editorial, 2019.

SAFLATE, Vladmir. O Estado suicidário. São Paulo: N-1., 2020

SCHUCMAN, Lia V. Entre o encardido, o branco e o branquíssimo: raça, hierarquia e poder na construçáo da branquitude paulistana. Doutorado [tese]. São Paulo: Universidade de São Paulo, 2012.

SILVA, Denise F. Ninguém: direito, racialidade e violência. Meritum, revista de Direito da Universidade FUMEC, v. 9, n. $1,2014$.

SILVA, Denise F. Sobre diferença sem separabilidade. 32a Bienal de São Paulo: Incerteza Viva: Catálogo. VOLZ, Jochan; REBOUÇAS, Julia. (Orgs.) São Paulo: Fundação Bienal de São Paulo, 57-66, 2016. 
SILVA, Priscila E. O conceito de branquitude: reflexôes para o campo de estudo. In: MULLER, M.P.T.; CARDOSO, L. (Orgs.). Branquitude. Estudos sobre a identidade branca no Brasil. Curitiba: Appris, 2017,.p. 19-32.

SOUZA, Flavia de A. O saber-corpo e a busca pela descolonização da saúde coletiva. Saúde em debate. Rio de Janeiro. v. 43, n. especial 8, 189-202, 2019.

STREVA, Juliana M. Teoria Descolonial de Frantz Fanon: anti-racismo, novo humanismo e luta. In: Conversaçóes: Política, Teoria e Direito - Revista discente da Pós Graduação - PUC-Rio. Cadernos do Seminário da Pós. ISSN 21769826. 120150,2015

VARGAS, István V.D.; CARDOSO, Raimundo L.S. Controle da hipertensão arterial sistêmica na população negra no Maranhão: problemas e desafios. Saúde Soc. São Paulo, v.25, n.3, 664-671, 2016.

VIEIRA DA SILVA, Ligia Maria. O campo da saúde coletiva: gênese, transformações e articulações com a reforma sanitária brasileira. 2018. p. 269-269.

WEBER, Max. Ensaios de sociologia. 5. Ed. Rio de Janeiro: Guanabara Koogan, 2002. 